\title{
ANALISA STRUKTUR PELIMPAH BENDUNGAN LUBUK AMBACANG KECAMATAN HULU KUANTAN KABUPATEN KUANTAN SINGINGI PROVINSI RIAU
}

\author{
Nur Sholawatini $^{1}$, Evi Nur Cahya ${ }^{2}$, Heri Suprijanto ${ }^{2}$ \\ ${ }^{1}$ Mahasiswa Program Sarjana Teknik Pengairan Universitas Brawijaya \\ ${ }^{2}$ Dosen Jurusan Teknik Pengairan Fakultas Teknik Universitas Brawijaya \\ Teknik Pengairan Universitas Brawijaya-Malang, Jawa Timur, Indonesia \\ Jalan MT. Haryono 167 Malang 65145, Indonesia \\ e-mail: nursholawatini@gmail.com
}

\begin{abstract}
ABSTRAK: Bendungan Lubuk Ambacang merupakan bendungan beton gilas padat (Roller Compacted Concrete) yang berada di Sungai Indragiri, struktur pelimpah juga menjadi bagian bendungan dan penting keberadaannya. Tujuan dari studi ini untuk mengetahui daerah kritis pada struktur ketika terjadi gempa. Analisa hidrolika dilakukan untuk menentukan lebar pelimpah yang sesuai. Analisa stabilitas dilakukan untuk mengetahui struktur yang direncanakan telah aman terhadap guling dan geser. Daya dukung tanah juga dianalisa untuk mengetahui struktur tanah mempunyai kapasitas yang cukup untuk menahan beban di atasnya. Pembebanan di analisa dalam beberapa kondisi, baik dalam keadaan normal maupun gempa Operating Basic Earthquake (OBE) dan Maximum Design Earthquake (MDE). Perencanaan struktur pelimpah dilakukan berdasarkan analisis pelat cangkang beton bertulang menggunakan aplikasi STAADPro V8i. Dari hasil studi didapatkan lebar pelimpah sebesar 51 meter yang aman terhadap guling dan geser. Daya dukung tanah mampu menahan tegangan yang terjadi pada bangunan. Hasil STAAD.Pro V8i menunjukkan bahwa daerah kritis pelimpah terjadi pada bagian hulu pelimpah ketika kondisi air waduk normal dan saat terjadi gempa OBE. Sedangkan saat kondisi Probable Maximum Flood (PMF) daerah kritis berada di saluran peluncur. Untuk bagian peredam energi, daerah kritis terjadi pada hulu struktur ketika kondisi $\mathrm{Q}_{100 t h}, 1,25 \mathrm{Q}_{100 t h}$ normal dan saat gempa OBE.
\end{abstract}

Kata kunci: Pelimpah Overflow, Struktur Pelimpah, Stabilitas Struktur, Pelat Cangkang, Beton Gilas Padat.

ABSTRACT: Lubuk Ambacang Dam is Roller Compact Concrete Dams and located on the Indragiri River, where the overflow spillway structure also important part of the dam. The purpose of this study is to find out the critical area in the structure when an earthquake occurs. Hydraulic analysis determine the appropriate spillway width. Stability analysis is find out that the planned structure is safe from overturning and sliding. The bearing capacity of the soil is also analyzed to determine whether the soil structure has sufficient capacity to withstand the structure load. Structure load are analyzed in normal conditions, Operating Basic Earthquake (OBE) and Maximum Design Earthquake (MDE). Planned of spillway structure based on the analysis of shell plates using STAADPro V8i application. Result of this study, spillway width is 51 meters which is safe from overturning and sliding. Bearing capacity of the soil is able to withstand the structure stress. The results of STAAD.Pro V8i show that the spillway critical area occurs in the upstream part of spillway when the reservoir water conditions are normal and when the OBE occurs. Whereas the Probable Maximum Flood (PMF) condition, critical area is in chuteway channel. For the stilling basin, the critical area occurs in the upper structure when the conditions are $Q_{100 t h}, 1.25 Q_{100 t h}$ normal and during an $O B E$.

Keyword: Overflow Spillway, Spillway Structure, Stability of Structure, Shell Plates, Roller Compact Concrete. 
Bendungan Lubuk Ambacang dibangun dengan tujuan untuk menampung air hujan pada musim kemarau, agar bisa dimanfaatkan untuk memenuhi kebutuhan air di daerah irigasi. Disamping itu, tujuan utama dari pembangunan bendungan yaitu sebagai sarana untuk mengendalikan banjir, pembangkit tenaga listrik, melestarikan tanah, pengendali erosi.

Mengkaji dari permasalahan yang ada di atas, salah satu faktor terbesar Bendungan Lubuk Ambacang dibangun adalah untuk dapat mengendalikan banjir yang sangat sering terjadi. Agar fungsi bendungan sebagai pengendali banjir optimal, maka perencanaan bangunan utama dan pelengkap pada bendungan harus detail dan teliti. Salah satunya adalah bangunan pelimpah. Bangunan pelimpah sendiri merupakan bagian dari suatu bendungan yang memiliki fungsi untuk membuang kelebihan air ke arah hilir bendungan. Ditinjau dari bendungan yang bersangkutan, pelimpah menghindarkan ketinggian air yang melampaui tinggi air maksimum yang direncanakan. Ditinjau dari kepentingan bagian hilir, pelimpah menyalurkan air yang tidak dipergunakan oleh bendungan yang bersangkutan.

Sehubungan dengan pemaparan diatas, maka diperlukan studi untuk merencanakan pembangunan Bendungan Lubuk Ambacang. Salah satunya yakni dengan melakukan Studi Perencanaan Bangunan Pelimpah Bendungan Lubuk Ambacang, Kabupaten Kuantan Singingi.

\section{BAHAN DAN METODE}

Lokasi Bendungan Lubuk Ambacang berada di Sungai Indragiri. Secara administratif terletak pada Kecamatan Hulu Kuantan, Kabupaten Kuantan Singingi, Provinsi Riau. Letak geografis rencana lokasi Bendungan Lubuk Ambacang terletak pada sekitar 00'36'46,6" Lintang Selatan dan 101 '19'27,7' Bujur Timur.

Data-data yang diperlukan untuk mengerjakan studi ini antara lain adalah data peta topografi, data hidrologi berupa debit banjir rancangan, data mekanika tanah dan geologi

Untuk tahapan studi meliputi analisa hidrolika, stabilitas struktur dan analisa struktur. Berikut merupakan metode dan bahan yang digunakan dalam studi,
1. Analisa Hidrolika Pelimpah

a. Kapasitas Ambang Pelimpah

Pada buku Konstruksi Bendungan Urugan Pelimpah menjelaskan bahwa rumus debit yang melalui pelimpah dengan penampang segiempat adalah sebagai berikut (Masrevaniah, 2012):

$Q=C L H^{\frac{3}{2}}$

dengan:

$\mathrm{Q}=$ Debit banjir rancangan $\left(\mathrm{m}^{3} /\right.$ detik $)$

$\mathrm{L} \quad=$ Lebar efektif ambang pelimpah (m)

$\mathrm{C}=$ Koefisien debit

$\mathrm{H} \quad=$ Tinggi tekan di atas ambang $(\mathrm{m})$

b. Koefisien Debit

Koefisien debit dapat ditentukan berdasarkan rumus empiris Iwasaki (Anggara dkk, 2017):

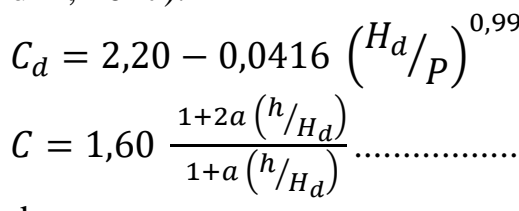

dengan:

$\mathrm{C}=$ Koefisien debit untuk semua tinggi tekan

$\mathrm{C}_{\mathrm{d}}=$ Koefisien debit untuk tinggi tekan rencana

$\mathrm{h}=$ Tinggi air di atas mercu ambang

$\mathrm{H}_{\mathrm{d}}=$ Tinggi tekan rencana di atas mercu ambang

$\mathrm{P}=$ Tinggi ambang

$\mathrm{a}=$ Konstanta (diperoleh saat $\mathrm{h}=\mathrm{H}_{\mathrm{d}}$ yang berarti $\mathrm{C}=\mathrm{C}_{\mathrm{d}}$ )

\section{c. Lebar Efektif Ambang Pelimpah}

Ketika terjadi limpahan di atas ambang pelimpah, akan terjadi kontraksi aliran pada pilar-pilar maupun pada kedua dinding samping.

Debit air yang melewati mercu ambang didasarkan pada lebar efektifnya. Besarnya perbandingan antara $B_{\text {eff }}$ dan $\mathrm{B}$ dipengaruhi oleh bentuk pilar bagian hulu, tembok tepi dan kedalaman air (Moh. Lutfi, dkk, 2018):

$L_{e f f}=L-2\left(N . K_{p}+K_{a}\right) H$

dengan:

$\mathrm{B}_{\text {eff }}=$ Panjang efektif pelimpah (m)

$\mathrm{B}=$ Panjang pelimpah yang sebenarnya $(\mathrm{m})$

$\mathrm{N}$ = Jumlah pilar pada pelimpah

$\mathrm{Kp}=$ Koefisien kontraksi pada pilar

$\mathrm{Ka}=$ Koefisien kontraksi pada dinding samping pelimpah

$\mathrm{H}=$ Tinggi tekan total di atas mercu pelimpah (m) 
Koefisien kontraksi pilar ditentukan sebagai berikut (Kp):

- Pilar dengan bentuk depan persegi : :0,02

- Pilar dengan bentuk depan bulat : 0,01

- Pilar dengan bentuk depan runcing : 0,01

Koefisien kontraksi tembok tepi sebagai berikut (Ka):

- Tembok tepi bersudut runcing $\quad: 0,2$

- Tembok tepi bersudut bulat/tumpul : 0,1

\section{d. Profil Ambang}

Pada studi ini menggunakan ogee tipe IV, yaitu dengan kemiringan hulu ambang 3:3. Perencanaan ogee IV tersajikan pada Gambar 1 di bawah ini,

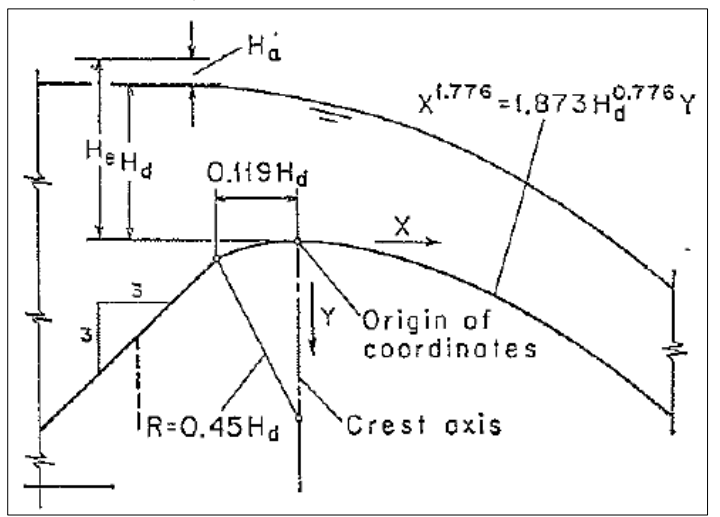

Gambar 1. Profil ambang pelimpah tipe IV

Sumber: Chow (1985)

Tipe depan miring sesuai untuk head yang tinggi, bentuk seperti ini menambah gaya vertikal, sehingga dapat menambah stabilitas konstruksi.

\section{e. Saluran Peluncur}

Aliran yang terjadi pada saluran peluncur adalah aliran superkritis dan tidak diperbolehkan adanya konstruksi yang dapat menghambat (misalnya pilar, ambang) di dalamnya. Dikarenakan aliran superkritis maka aliran merupakan aliran tidak seragam dan aliran dengan percepatan. Metode perhitungan penentuan aliran pada saluran peluncur ini menggunakan metode kekekalan energi (tahapan standar). Persamaan energinya adalah sebagai berikut (Sosrodarsono, 1977),

$$
Z_{1}+\alpha_{1} \frac{V_{1}^{2}}{2 g}=Z_{2}+\alpha_{1} \frac{V_{2}^{2}}{2 g}+h_{f}+h_{e}
$$

\section{f. Peredam Energi}

Bangunan peredam energi yang cocok digunakan untuk debit yang besar dan aliran dengan tekanan hidrostatis yang tinggi (bilangan Froude $>4,5, \mathrm{q}>45 \mathrm{~m}^{3} / \mathrm{dt} / \mathrm{m}$ dan tekanan hidrostatis > $60 \mathrm{~m}$ ) adalah kolam peredam energi tipe II. Peredam energi tipe II dapat dilihat pada Gambar 2.

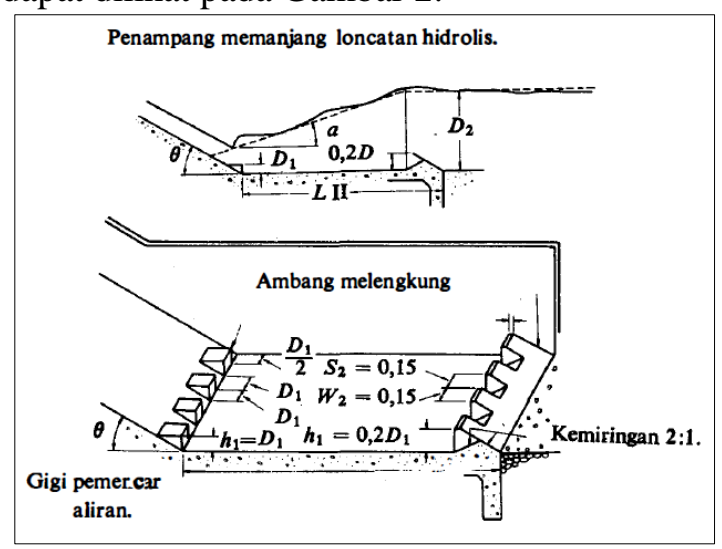

Gambar 2. Kolam Olakan Datar Tipe II

Sumber: M. Shafai, dkk (2009)

2. Analisa Stabilitas Struktur

a. Guling

Stabilitas terhadap guling dihitung dengan menggunakan rumus:

- Keadaan normal (Varshney, 1977)

$S F=\frac{\sum M_{V}}{\sum M_{h}}>2,5$

- Keadaan ekstrim

$S F=\frac{\sum M_{V}}{\sum M_{h}}>1,5$

dengan:

$S F=$ angka keamanan (safety factor)

$\mathrm{Mv}=$ momen-momen vertikal (t.m)

$\mathrm{Mh}=$ momen-momen horisontal (t.m)

b. Geser

Stabilitas terhadap geser (sliding) dihitung dengan menggunakan rumus (Varshney, 1977):

- Keadaan normal

$$
S F=\frac{f \cdot \sum V+\tau \cdot A}{\sum H} \geq 5
$$

- Keadaan ektrim

$$
S F=\frac{f \cdot \sum V+\tau \cdot A}{\sum H} \geq 4
$$

dengan:

$S F=$ Angka keamanan

$\mathrm{f} \quad=$ Koefisien geseran antara beton dengan beton atau beton dengan batuan pondasi $(\operatorname{tg} \phi)$

$\phi \quad=$ Tegangan geser antara tanah terhadap pondasi $\left({ }^{\circ}\right)$

$\sum v=$ Jumlah gaya vertikal (ton)

$\tau=$ Tegangan geseran pada beton terhadap batuan pondasi. Nilai tegangan ini bervariasi, dari $140 \mathrm{t} / \mathrm{m}^{2}$ untuk batuan yang jelek sampai $500 \mathrm{t} / \mathrm{m}^{2}$ untuk batuan yang bagus 
$\Sigma H=$ Jumlah gaya horisontal (ton)

$\mathrm{A}=$ Luas permukaan pondasi,

Untuk bendungan beton dengan ketinggian diatas $150 \mathrm{~m}$ nilai keamanannya adalah 4 untuk keadaan normal, dan untuk kondisi ekstrim adalah 3 .

\section{c. Daya Dukung Tanah}

Perhitungan daya dukung tanah menggunakan rumus dari Terzaghi. Mengenai koefisien daya dukung, pada Terzaghi memberikan nilai yang berlainan untuk keadaan keruntuhan setempat dan keruntuhan umum. Akan tetapi dalam prakteknya sangat sulit untuk memprediksi keruntuhan seperti apa yang nantinya akan terjadi. Berdasarkan statistika percobaan pembebanan, Ohsaki mengusulkan rumus untuk perhitungan daya dukung batas yang merupakan modifikasi dari rumus Terzaghi (Sosrodarsono, 2000), adapun rumusnya adalah sebagai berikut

$\mathrm{q}_{\mathrm{u}}=\alpha \cdot c \cdot N_{c}+\beta \cdot \gamma \cdot B \cdot N_{\gamma}+\gamma \cdot D_{f} \cdot N_{q}(10)$ dengan:

$\mathrm{q}_{\mathrm{u}} \quad=$ daya dukung batas ton $/ \mathrm{m}^{2}$

$\alpha \quad=$ faktor bentuk

$\beta \quad=$ faktor bentuk

c $\quad=$ kohesi tanah $\left(\operatorname{ton} / \mathrm{m}^{2}\right)$

$\gamma \quad=$ berat jenis tanah $\left(\mathrm{ton} / \mathrm{m}^{3}\right)$

$\mathrm{B}=$ lebar pondasi (m)

$\mathrm{N}_{\mathrm{c}}, \mathrm{N}_{\mathrm{q}}, \mathrm{N}_{\gamma}=$ tergantung dari sudut geser dalam

Dalam mendesain bangunan yang aman terhadap daya dukung batas, maka daya dukung yang diijinkan harus diterima. Keamanan daya dukung ini didapat dengan membagi daya dukung batas dengan suatu harga faktor keamanan antara 2 (normal) sampai 3 (gempa).

d. Angka Keamanan Tebal Lantai Peredam Energi

Tebal lantai perlu diperhatikan keamanannya untuk menghindari terjadi kerusakan pada lantai tersebut. Ketebalan lantai dapat dikontrol menggunakan persamaan sebagai berikut (Kementrian PU-SDA, 2013):

$\mathrm{dx} \geq S \frac{P_{x}-W_{x}}{\gamma}$

dengan:

$\mathrm{dx}=$ ketebalan lantai pada titik $\mathrm{x}(\mathrm{m})$

$\mathrm{S}=$ faktor keamanan $(1,25$ untuk kondisi gempa dan 1,5 untuk kondisi normal)

Px = uplift pada titik $\mathrm{x}\left(\mathrm{kg} / \mathrm{m}^{2}\right)$

$\mathrm{Wx}=$ kedalaman air pada titik $\mathrm{x}(\mathrm{m})$

$\gamma=$ berat jenis bahan $\left(\mathrm{kg} / \mathrm{m}^{3}\right)$

\section{Analisa Struktur}

Pembebanan pada analisa struktur menggunakan aplikasi STAAD.Pro v8i. Pada pembebanan struktur ambang pelimpah di analisa pada tujuh kondisi yaitu pada pasca konstruksi, pada waduk dengan elevasi normal, waduk dengan air banjir standar proyek, konstruksi dengan gempa dasar OBE (Operating Basic Earthquake), waduk elevasi air normal dengan gempa dasar OBE, waduk elevasi normal dengan gempa maksimum MDE (Maximum Design Earthquake) dan PMF (Probability Maximum Flood).

Sedangkan lantai peredam energi, pembebanan di analisis dalam 6 kondisi yaitu, $\mathrm{Q}_{100 \text { th }}$ dan $1,25 \mathrm{Q}_{100 \text { th }}$ dalam keadaan normal, dengan gempa OBE dan dengan gempa MDE.

\section{HASIL DAN PEMBAHASAN}

\section{Analisa Hidrolika}

1. Ambang Pelimpah

Pada studi ini, lebar pelimpah direncanakan memiliki lebar 51 meter dengan 6 pintu (1 pintu $=8,5$ meter). Masing-masing pintu dibatasi oleh pilar. Lebar pilar 3 meter dengan jumlah 5 buah pilar, sehingga total lebar pelimpah dengan pilar adalah 66 meter. Untuk perencanaan profil pelimpah menggunakan debit outflow maksimum dengan kala ulang $\mathrm{Q}_{100 \text { th. }}$. Debit outflow maksimum $\mathrm{Q}_{100 \text { th }}$ adalah $5413,372 \mathrm{~m}^{3} / \mathrm{dt}$ dengan kedalaman aliran di atas ambang pelimpah (Hd) $14,210 \mathrm{~m}$ dan rencana kemiringan hilir pelimpah adalah 1 : 0,85 .

Profil ambang pelimpah didesain menggunakan OGEE Tipe IV dengan hasil perhitungan sebagai berikut:

$$
\begin{aligned}
& \mathrm{R} \quad=0,45 \mathrm{Hd}=6,394 \mathrm{~m} \\
& \text { Jarak R }=0,119 \mathrm{Hd}=1,691 \mathrm{~m} \\
& \text { Perhitungan lengkung Harrold: } \\
& x^{1,776}=1,873 \cdot H d^{0,776} \cdot Y \\
& \text { maka: } \\
& \mathrm{Y} \quad=0,068 \cdot \mathrm{X}^{1,776} \\
& \mathrm{Y}^{\prime} \quad=0,121 \cdot \mathrm{X}^{0,776}
\end{aligned}
$$

Titik awal melalui gradient:

Misal

$$
\begin{aligned}
\mathrm{Y}^{\prime} & =1 / \mathrm{Z} \\
\mathrm{Y}^{\prime} & =1 / 0,85 \\
& =1,176 \\
\mathrm{Y}^{\prime} & =0,121 \cdot \mathrm{X}^{0,776} \\
1,176 & =0,121 \cdot \mathrm{X}^{0,776} \\
\mathrm{X}^{0,776} & =9,729 \\
\mathrm{X} & =18,763 \\
\mathrm{Y} & =0,068 \cdot \mathrm{X}^{1,776} \\
\mathrm{Y} & =12,429
\end{aligned}
$$


Maka koordinat titik akhir kurva (18.763 ; 12,429)

\section{Saluran Peluncur}

Untuk menghitung profil muka air pada saluran peluncur digunakan rumus persamaan energi dengan menggunakan debit $\mathrm{Q}_{100 \text { th }}$ Berikut ini merupakan kondisi perencanaan saluran peluncur:

- Kemiringan saluran peluncur :0,85

- Lebar saluran hulu

$: 51,000 \mathrm{~m}$

- Lebar saluran hilir

$: 66,000 \mathrm{~m}$

- Elevasi dasar saluran hulu $\quad:+113,500$

- Elevasi dasar saluran hilir $\quad:+48,500$

Perhitungan profil muka air pada saluran peluncur dihitung tiap pias dengan total jarak horisontal sebesar 63,4484 meter, dengan membagi menjadi 10 pias.

Debit per satuan lebar pada section 0 sampai akhir section 4 (berjarak 32,241 meter dari hulu pelimpah) adalah $106,145 \mathrm{~m}^{3} / \mathrm{dt} / \mathrm{m}$. Sedangkan untuk section 5 sampai akhir section 10 memiliki debit per satuan lebar sebesar $82,021 \mathrm{~m}^{3} / \mathrm{dt} / \mathrm{m}$.

\section{Peredam Energi}

Perencanaan desain peredam energi dihitung menggunakan debit kala ulang $\mathrm{Q}_{100 \mathrm{th}}$ dan dikontrol menggunakan debit $\mathrm{Q}_{1000 \mathrm{th}}$. Dari hasil perhitungan profil muka air peredam energi $\mathrm{Q}_{100 t \mathrm{th}}$ didapatkan:

- Debit per satuan lebar saluran

$$
\mathrm{q}=82,021 \mathrm{~m}^{3} / \mathrm{dt} / \mathrm{m}
$$

- Kecepatan aliran di akhir sal peluncur

$$
\mathrm{V}=38,653 \mathrm{~m} / \mathrm{det}
$$

- Bilangan Froude di akhir sal peluncur

- $\mathrm{F}_{1}=8,472$

Sehingga direncanakan menggunakan Kolam Olak USBR tipe II $\left(\mathrm{q}>45 \mathrm{~m}^{3} / \mathrm{dt} / \mathrm{m}, \mathrm{V}\right.$ $>18 \mathrm{~m} / \mathrm{dt}$, Fr > 4,5). Gambar 3 merupakan perhitungan Kolam Olak USBR tipe II pada studi. Berikut ini merupakan perhitungan Kolam Olak USBR tipe II:

$$
\begin{array}{lll}
\mathrm{h}_{1}=\mathrm{D}_{1} & =2,122 \mathrm{~m} & =2,2 \mathrm{~m} \\
\mathrm{w}_{1}=\mathrm{D}_{1} & =2,122 \mathrm{~m} & =2,2 \mathrm{~m} \\
\mathrm{~S}_{1}=\mathrm{D}_{1} & =2,122 \mathrm{~m} & =2,2 \mathrm{~m} \\
0,5 \mathrm{D}_{1} & =1,061 \mathrm{~m} & =1,1 \mathrm{~m} \\
\mathrm{~h}_{2}=0,2 \mathrm{~d}_{2} & =4,877 \mathrm{~m} & =5 \mathrm{~m} \\
\mathrm{~S}_{2}=0,15 \mathrm{D}_{2} & =3,658 \mathrm{~m} & =3,7 \mathrm{~m} \\
\mathrm{~W}_{2}=0,15 \mathrm{D}_{2} & =3,658 \mathrm{~m} & =3,7 \mathrm{~m}
\end{array}
$$

Menentukan panjang Kolam Olak tipe USBR II dapat dihitung dengan menggunakan grafik berikut ini:

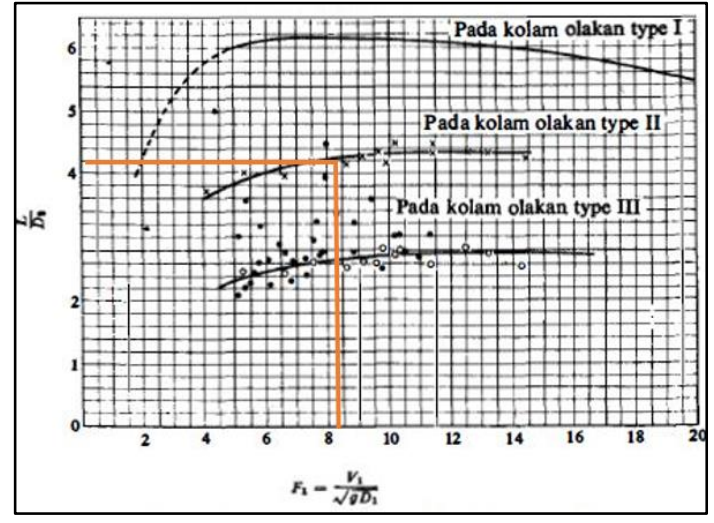

Gambar 3. Grafik untuk menentukan panjang loncatan

$$
\begin{aligned}
\frac{L}{D_{2}} & =4,200(\text { dari gambar } 3) \\
\mathrm{D}_{2} & =24,385 \\
\mathrm{~L} & =4,2 \times \mathrm{D}_{2} \\
& =4,2 \times 24,385 \\
& =102,903 \mathrm{~m}, \text { direncanakan } 103 \mathrm{~m}
\end{aligned}
$$

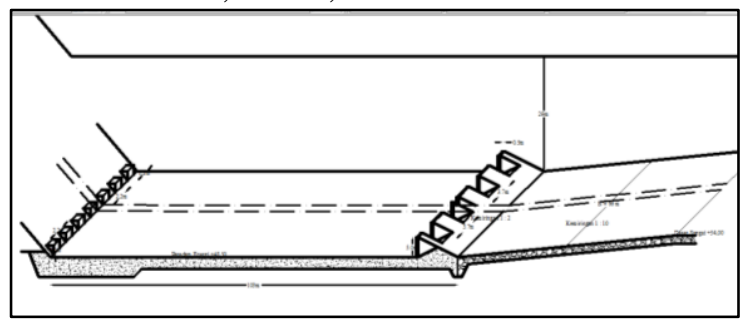

Gambar 4. Detail peredam energi USBR Tipe II

Dengan menggunakan desain peredam energi tersebut dan setelah melakukan kontrol terhadap escape channel, menunjukkan hasil yang tidak berbeda jauh pada ketinggian muka airnya. Sehingga kemungkinan terjadi backwater kecil.

\section{Analisa Stabilitas}

Perhitungan daya dukung izin tanah pada ambang pelimpah mengunakan hasil uji laboratorium BA 15-1. Dengan menggunakan rumus (10) didapatkan nilai daya dukung untuk pelimpah adalah 27311,060 ton $/ \mathrm{m}^{2}$ pada kondisi normal dan untuk kondisi gempa 18207,373 ton $/ \mathrm{m}^{2}$.

Hasil perhitungan stabilitas pada pelimpah menunjukkan hasil aman pada semua kondisi, baik pada stabilitas terhadap guling, geser, maupun daya dukung. Untuk tebal lantai peredam energi yang setebal 3 meter mampu menahan tekanan air baik dari atas bangunan (vertikal air) maupun bawah bangunan (uplift).

\section{Analisa Struktur}

Dengan menggunakan aplikasi STAAD.Pro V8i, didapatkan momen Mx dan My terbesar 
dalam masing-masing kondisi pembebanan. Tiga kondisi yang paling kritis adalah ketika kondisi air waduk normal, kondisi air waduk normal dengan gempa OBE dan PMF.

Gambar 5 dan Gambar 6 merupakan kondisi pada elevasi air waduk normal, daerah kritis tampak berada pada bagian hulu ambang pelimpah.

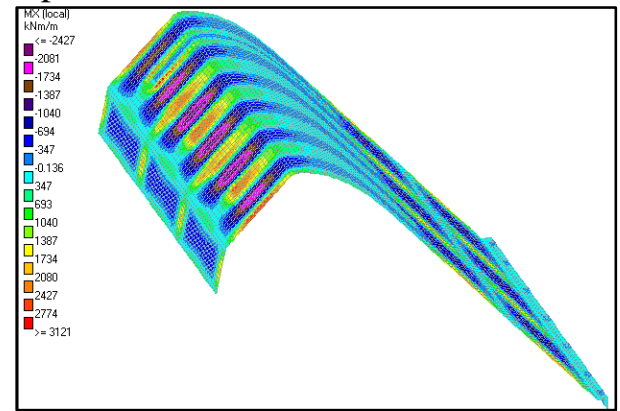

Gambar 5. Momen Mx pada pelimpah kondisi elevasi air waduk normal

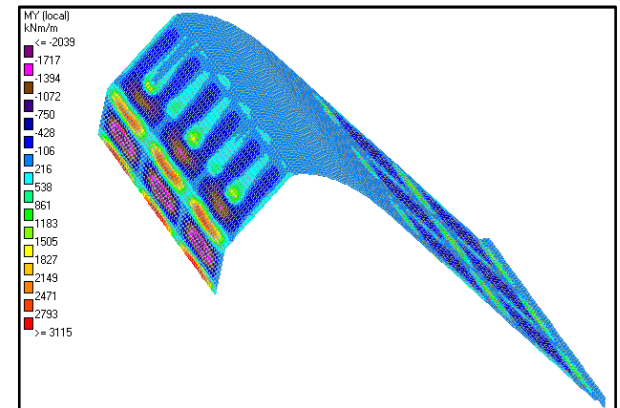

Gambar 6. Momen My pada pelimpah kondisi elevasi air waduk normal

Gambar 7 dan Gambar 8 merupakan kondisi pada elevasi air normal dengan gempa dasar operasi (OBE), dari gambar terlihat bahwa daerah kritis struktur berada pada bagian hulu ambang pelimpah.

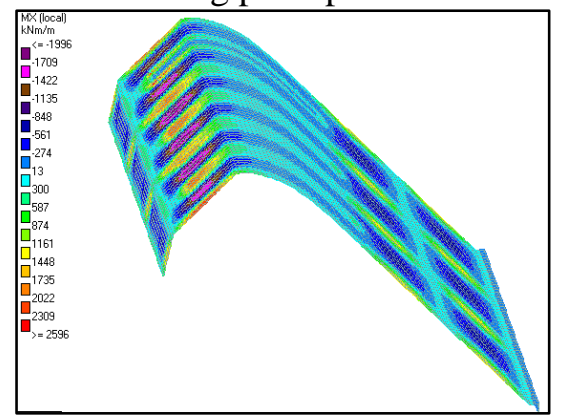

Gambar 7. Momen Mx pada pelimpah kondisi elevasi air normal dengan gempa dasar operasi (OBE)

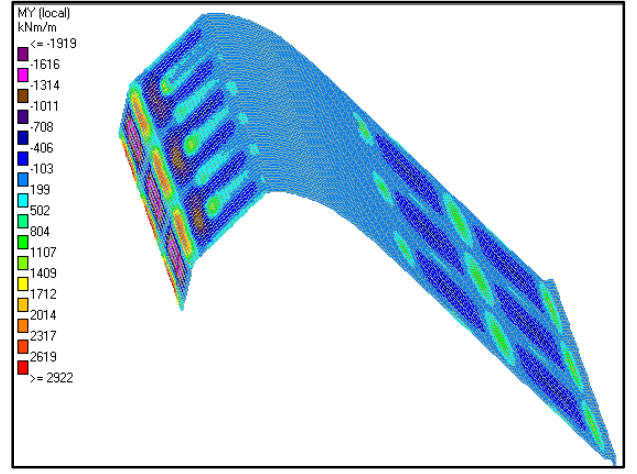

Gambar 8. Momen My pada pelimpah kondisi elevasi air normal dengan gempa dasar operasi (OBE)

Gambar 9 dan Gambar 10 merupakan kondisi pada elevasi air PMF, dari gambar terlihat bahwa daerah kritis berada pada bagian saluran peluncur.

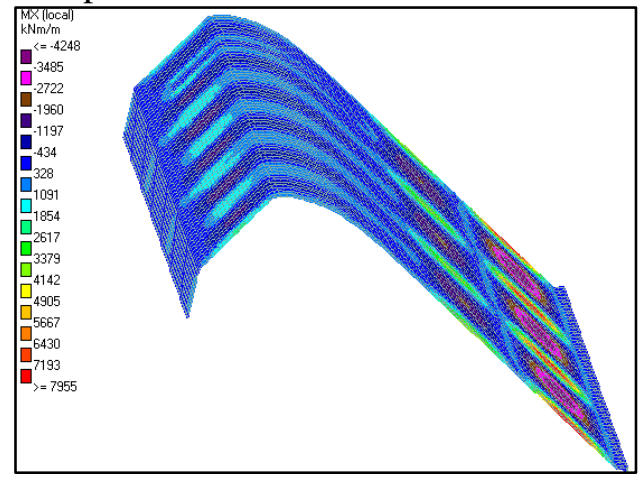

Gambar 9. Momen Mx pada pelimpah kondisi PMF

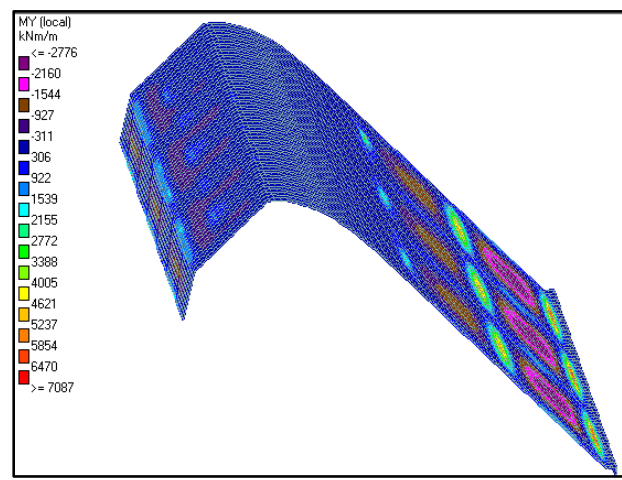

Gambar 10. Momen My pada pelimpah kondsi PMF

Dari tujuh kondisi pembebanan, kondisi paling kritis pelimpah terjadi saat PMF, dengan momen maksimum $\mathrm{Mx}$ sebesar $7955,370 \mathrm{kNm}$ dan momen maksimum My sebesar 7086,794 kNm.

Dengan momen tersebut didapatkan detail penulangan pada pelimpah adalah

- D36 - 70 (tulangan utama) dan D32 - 60 (tulangan bagi) pada daerah kritis. Daerah 
kritis ditentukan pada hulu pelimpah dikarenakan saat kondisi air waduk normal daerah kritis selalu terjadi pada daerah tersebut.

- Sedangkan untuk bagian lain menggunakan D32 - 100 (tulangan utama) dan D22 - 100 (tulangan bagi).

Momen yang digunakan pada struktur lantai peredam energi ada empat yaitu max Mx, min Mx, max My dan min My. Kondisi paling kritis terjadi ketika $\mathrm{Q}_{100 \text { th }}$ normal, $1,25 \mathrm{Q}_{100 \text { th }}$ normal dan $1,25 \mathrm{Q}_{100 t h}$ dengan gempa OBE. Ketiga kondisi tersebut tersajikan pada Gambar 11 sampai Gambar 16, tampak pada gambar bahwa daerah kritis selalu terjadi pada hulu struktur.

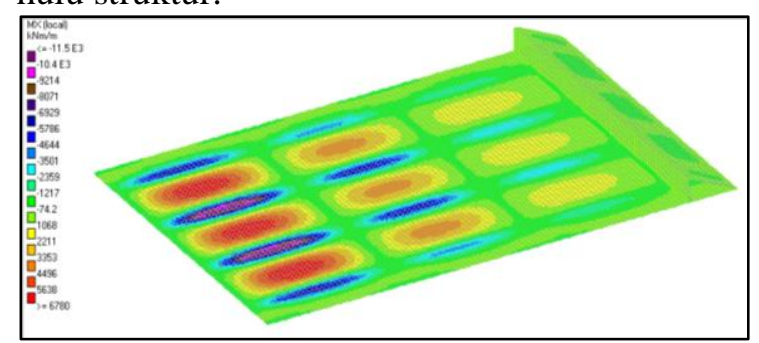

Gambar 11. Momen Mx pada lantai peredam energi kondisi biasa $-\mathrm{Q}_{100 \text { th }}$ normal

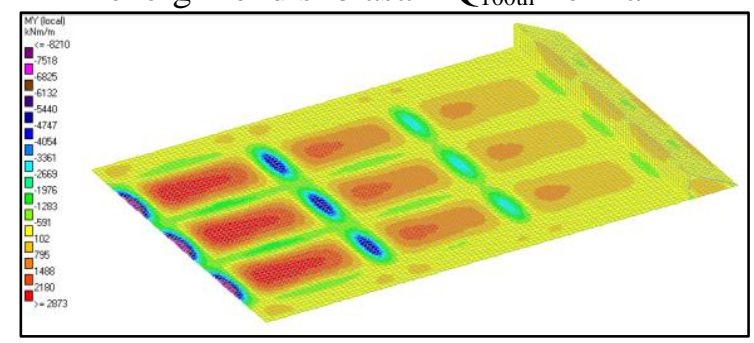

Gambar 12. Momen My pada lantai peredam energi kondisi biasa $-\mathrm{Q}_{100 \text { th }}$ normal

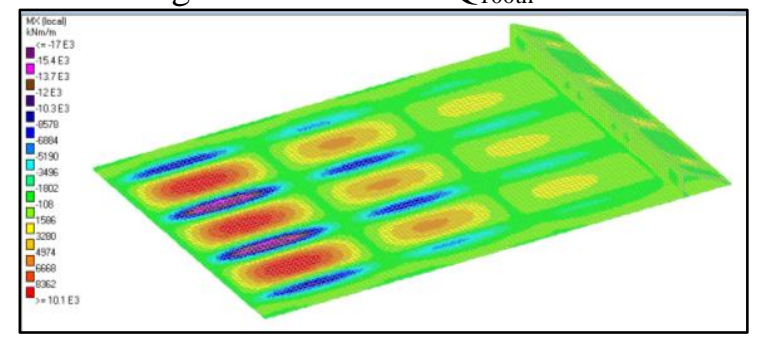

Gambar 13. Momen Mx pada lantai peredam energi kondisi biasa $-1,25 \mathrm{Q}_{100 \text { th }}$ normal

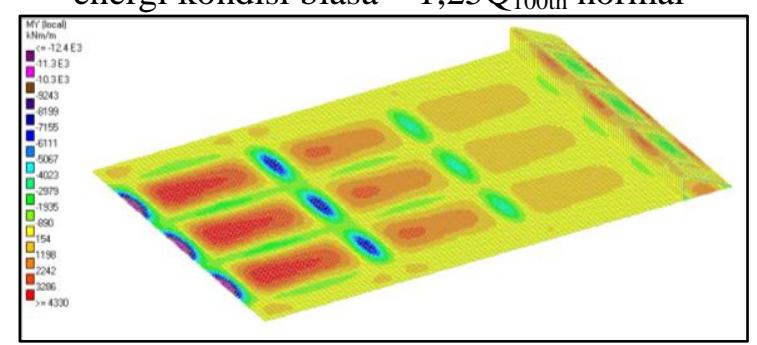

Gambar 14. Momen My pada lantai peredam energi kondisi biasa $-1,25 \mathrm{Q}_{100 \text { th }}$ normal

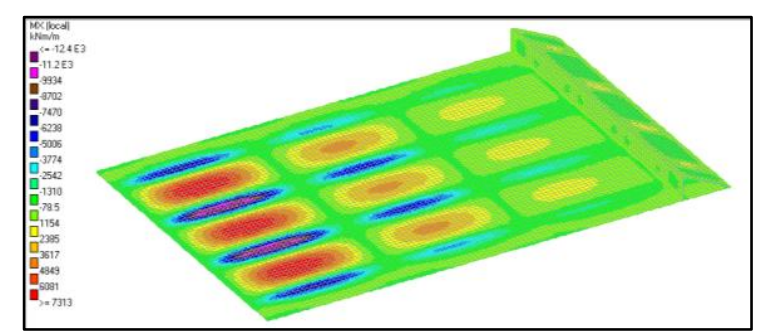

Gambar 15. Momen Mx pada lantai peredam energi kondisi luar biasa-1,25 $\mathrm{Q}_{100 \text { th }} \mathrm{OBE}$

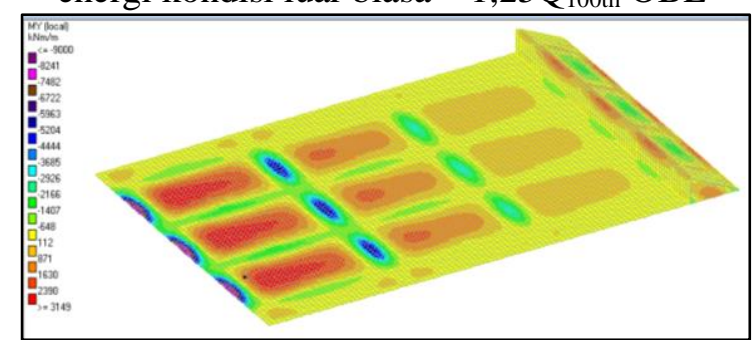

Gambar 16. Momen My pada lantai peredam energi kondisi luar biasa $-1,25 \mathrm{Q}_{100 \text { th }} \mathrm{OBE}$

Adapun nilai momen yang didapatkan pada lantai peredam energi adalah $17047,879 \mathrm{kNm}$ untuk max Mx, 12375,633 kNm untuk max My, 10056,042 untuk min Mx, dan 8703,644 untuk min My. Momen tersebut terjadi ketika keadaan $\mathrm{Q}_{100 \text { th }}$ normal.

Dengan momen tersebut, penulangan pada lantai peredam energi menggunakan 2D36 100 (tulangan utama tarik), D22 - 70 (tulangan bagi tarik), D28 - 175 (tulangan utama tekan) dan D22 - 120 (tulangan bagi tekan).

Adanya distribusi momen yang tampak pada Gambar 5 sampai 16 terjadi karena adanya contraction joint.

\section{KESIMPULAN}

Berdasarkan analisa perhitungan yang telah dilakukan pada studi ini, dapat diambil beberapa kesimpulan.

Pelimpah langsung (overflow spillway) didesain menggunakan debit banjir rancangan kala ulang 100 tahun dan dikontrol dengan $1,25 \mathrm{Q}_{100}$. Dari analisa hidrolika, didapatkan lebar pelimpah efektif 51 meter dengan 6 pintu (1 pintu selebar 8,5 meter).

Air yang melewati saluran peluncur sudah dipastikan merupakan aliran superkritis. Sehingga pada bagian hilir saluran peluncur diberi bangunan peredam energi. Bangunan peredam energi didesain dengan lebar 66 meter menggunakan USBR tipe II dan dikontrol dengan saluran escape channel agar tidak terjadi backwater. Peredam energi memiliki panjang 103 meter. 
Dari hasil perhitungan stabilitas dan pada semua kondisi, didapatkan bahwa pelimpah aman dari guling, geser maupun eksentrisitas bangunan. Untuk memperkuat stabilitas, pada bagian pondasi diberikan grouting konsolidasi dan grouting tirai untuk mengatasi adanya uplift (gaya angkat).

Lantai peredam energi aman terhadap segala kondisi. Akan tetapi untuk mencegah adanya pull out (cabut) diberikan angkur pada bagian bawah struktur.

Analisa pembebanan menunjukkan bahwa daerah kritis pelimpah terjadi pada bagian hulu pelimpah ketika kondisi air waduk normal dan saat terjadi gempa OBE. Sedangkan saat kondisi PMF daerah kritis berada di saluran peluncur. Untuk bagian peredam energi, daerah kritis terjadi pada hulu struktur ketika kondisi $\mathrm{Q}_{100 \mathrm{th}}, 1,25 \mathrm{Q}_{100 \text { th }}$ normal dan saat gempa OBE.

\section{DAFTAR PUSTAKA}

Bentley Sustaining Infrastructure. (2012). STAAD.Pro V8i (Technical Reference Manual). USA: Bentley Sustaining Infrastructure

Wibowo, Anggara Cahyo., Very Dermawan dan Pitojo Tri Juwono. (2017). Pemodelan Numerik Pelimpah Samping Waduk Telagawaja Bali
Kabupaten Karangasem dengan Analisa Komputasi Fluida Dinamis, Jurnal Teknik Pengairan. VII (2):184192.

Chow, Ven Te. (1985). Hidrolika Saluran Terbuka (Open-Channel Hydraulics). Jakarta: Erlangga.

Masrevaniah, Aniek. (2012). Konstruksi Bendungan Urugan Pelimpah. Malang: CV Asrori.

Maulana, Moh. Lutfi., Eko Noerhayati dan Azizah Rachmawati. (2018). Studi Perencanaan Bangunan Pelimpah (Spillway) pada Bendungan Tugu Kabupaten Trenggalek, Jurnal Rekayasa Sipil. VI (2):155-164.

M. Shafai Bejestan and K. Neisi. (2009). A New Roughened Bed Hydraulic Jump Stilling Basin. Asian Journal of Applied Sciences. (2):436-445.

Sosrodarsono, Suyono dan Takeda, Kensaku. (1977). Bendungan Type Urugan. Jakarta: PT Pradnya Paramita.

United States Department of The Interior Bureau of Reclamation. (1973). Design of Small Dams. New York: U.S. Government Printing Office.

Varshney, Rama Shankar. (1977). Concrete Dams. New Delhi: Oxford \& IBH Publishing CO. 